\title{
Study on the effect of electrochemical treatment of nicosulfuron wastewater
}

\author{
Rui Zhao and Wenqiang Jiang* \\ College of environmental science and engineering, Qilu University of Technology (Shandong Academy of Sciences), Jinan 250353, \\ People's Republic of China
}

\begin{abstract}
Nicosulfuron, a kind of sulfonylurea herbicide, because of its high activity and low dosage, has been widely used in corn planting weeding. Electrochemical method was chosen to treat its simulated waste water and the influence factors such as current intensity, plate spacing and electrolyte $\mathrm{pH}$ on electrolysis effect were investigated. A double-coated titanium dioxide titanium plate was chosen as the anode accompanied with a single-coated titanium plate as the cathode. The results showed that the removal efficiency of nicosulfuron was the highest when the electrolyte $\mathrm{pH}=3$, the plate spacing is $1.5 \mathrm{~cm}$ and the current intensity is $0.8 \mathrm{~A}$. Under the optimal condition, the removal rate of nicosulfuron reached $86.6 \%$ after 7 hours electrolysis. Thus, electrochemical technology might provide a significant method to remove the synthetic organic compounds.
\end{abstract}

\section{Introduction}

Nicosulfuron has been widely used in corn planting weeding because of its high activity and low dosage. There are many kinds of methods to treat its waste water . Sabadie indicated that hydrolysis of nicosulfuron principally involves the breakdown of the urea part of the molecule at $30^{\circ} \mathrm{C}$ as $\mathrm{pH}$ ranging from 4 to 11 . Its rate constants decreased from $0.50 \mathrm{~d}^{-1}$ to $0.002 \mathrm{~d}^{-1}$ as $\mathrm{pH}$ increased from 4 to 8 , then remained stable under alkaline conditions[1]. Chen adopted advanced oxidation technology to increase the biodegradability of nicosulfuron, and then activated sludge process was used to improve the quality of effluent. The optimal removal rate of $83.2 \%$ was obtained through the optimization of the reaction process [2]. The toxic and harmful substances in the wastewater can not be completely removed only by biological treatment.

Advanced oxidation processes (AOPs) have been emerged as potentially powerful methods to remove organic pollutants in water through in situ generation of strong oxygen-based oxidizers, among which the formation of hydroxyl radical $(\cdot \mathrm{OH})$ is especially desired, since it is the strongest oxidizer and can react nonselectively with various types of organics [3]. Electrochemical oxidation is one of the AOPs and has drawn considerable research attention due to its robustness and simplicity in structure and operation [4].

In this study, the high performance liquid chromatographic method (HPLC) was estabilished to determine the concentration of nicosulfuron. The following parameters such as electrolyte $\mathrm{pH}$, plate spacing, and current intensity were studied in order to find the optimal electrolysis condition for nicosulfuron.

\footnotetext{
a Corresponding author: spge@163.com
}

The results might provide a theoretical basis for the electorchemical treatment of nicosulfuron wastewater.

\section{Experimental materials and methods}

\subsection{Experimental materials}

Nicosulfuron was selected as the model pollutant of electrolysis. It was a kind of industrial product obtained from Jingbo agricultural Polytron Technologies Inc. Its structure formula and general characteristics were given in Table 1.

Table 1. General characteristics of nicosulfuron.

\begin{tabular}{cc}
\hline Name & Nicosulfuron \\
Chemical structure & $\mathrm{C}_{15} \mathrm{H}_{18} \mathrm{~N}_{6} \mathrm{O}_{6} \mathrm{~S}$ \\
$111991-09-4$ \\
Molecular Formula \\
CAS Number \\
Molecular mass \\
Solubility & $\begin{array}{r}\text { acetonitrile } 2.3 \% \text {, acetone } 1.8 \%, \\
\text { ethanol } 0.45 \% \text {, water } 12 \%\end{array}$ \\
\hline
\end{tabular}

The other chemicals were of analytical reagent grade and used as received without further purification. 


\subsection{Experimental methods}

\subsubsection{Electrolysis}

A double-coated titanium dioxide titanium plate was chosen as the anode accompanied with a single-coated titanium plate of the same size as the cathode at a certain space between electrodes. To examine the influencing parameters, a volume of $400 \mathrm{~mL}$ nicosulfuron solution was used to conduct the electrocatalytic degradation experiments.

Electrolysis was performed with galvanostat to study the electrocatalytic performance of the electrodes. $3 \mathrm{~g}$ of anhydrous sodium sulfate was dissolve in the solution. During the experiments, samples were drawn from the reactor at certain time intervals and the concentration of nicosulfuron was quantitatively analyzed by a high performance liquid chromatography (LC-10ATvp, SHIMADZU Corporation, Japan), equipped with a N2000 data station. The column was chose to use an inertSustain $\mathrm{C} 18 \quad(4.6 \mathrm{~mm} \times 150 \mathrm{~mm} \times 5 \mu \mathrm{m})$, which was filled with octadecylsilane bonded silicao and its temperature was controlled at room temperature. The mobile phase was methanol, water and acetic acid $(60: 40: 2, \mathrm{~V} / \mathrm{V} / \mathrm{V})$. The eluent was delivered at a flow rate of $0.88 \mathrm{~mL} / \mathrm{min}$ and the absorbance at $254 \mathrm{~nm}$ was measured. The injection volume was $20 \mu \mathrm{L}$.

\subsubsection{Linear relationship between peak area and the concentration of nicosulfuron solution}

$0.2000 \mathrm{~g}$ nicosulfuron was accurately weighed and diluted to $2000 \mathrm{ml}$ with distilled water to obtain a standard solution of nicosulfuron at a concentration of $100 \mathrm{mg} / \mathrm{L}$. The standard solution was diluted to different concentrations, such as $1 \mathrm{mg} / \mathrm{L}, 5 \mathrm{mg} / \mathrm{L}, 10 \mathrm{mg} / \mathrm{L}, 25$ $\mathrm{mg} / \mathrm{L}, 50 \mathrm{mg} / \mathrm{L}$ and $100 \mathrm{mg} / \mathrm{L} .20 \mu \mathrm{L}$ solution was injected into the HPLC to determined the concentration of nicosulfuron. The linear relationship between the concentration of nicosulfuron and the peak area was analyzed and shown in Figure 1.

It could be seen from Figure 1 that there was a good linear relationship between the peak area and the concentration of nicosulfuron solution in the range of 0 $100 \mathrm{mg} / \mathrm{L}$, and the $\mathrm{R}^{2}$ value was 0.9996 .

In the next expeirments, the concentration of nicosulfuron could be calculated by equation 1 .

$$
\mathrm{C}=\frac{\mathrm{A}-16797.75}{18001.43167}
$$

\subsection{3 simple stirring control experiment method}

$400 \mathrm{~mL}$ of nicosulfuron solution was placed in the electrolytic cell and $3 \mathrm{~g}$ of anhydrous sodium sulfate was added into the solution. The electrolyte was continuously stirred for $9 \mathrm{~h}$ using a magnetic stirrer. Samples were taken at intervals of $3 \mathrm{~h}$ to be analyzed by using HPLC. The peak area of nicosulfuron was determined by chromatography.

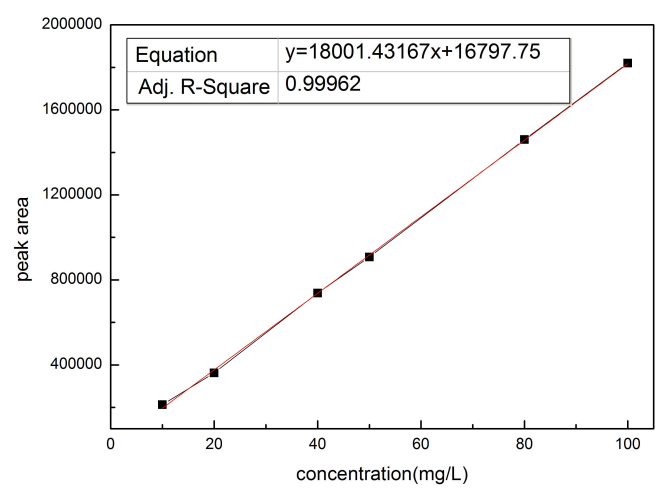

Figure 1. Linear relationship between peak area and the concentration of nicosulfuron solution

\section{Results and discussion}

\subsection{Simply stirring control experiment}

The degradation of nicosulfuron in stirring process was shown in Table 1 . There was little change in peak area during 9 hours stirring process, which indicated that nicosulfuron was stable under the condition of simple agitation. In all the subsequent electrolysis experiments, the reaction time was within 9 hours, therefore, the degradation of nicosulfuron due to stirring process could considered to be negligible.

Table 1. Change of peak area for nicosulfuron.

\begin{tabular}{ccccc}
\hline Time $(\mathrm{h})$ & 0 & 3 & 6 & 9 \\
\hline Peak area $\left(\times 10^{6}\right)$ & 1.820 & 1.819 & 1.821 & 1.819 \\
\hline
\end{tabular}

\subsection{Effect of current intensity}

The current intensity directly is a key experimental parameter that affects the electrochemical oxidation process as it regulates the capability of hydroxyl radical generation on the electrode, which gonverns the degradation efficiency of organic matter in aqueous solution[5]. However, the higher the current intensity is, the greater the power consumption is. Therefore, it is extremely necessary to choose a suitable current intensity to obtain a high electrolysis efficiency with low energy consumption.

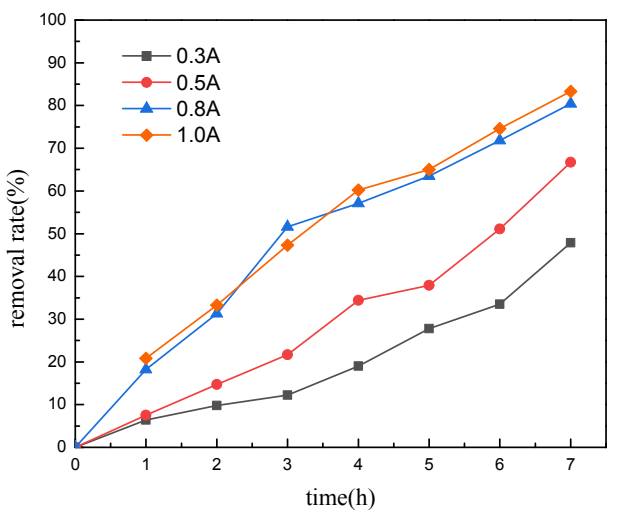

Figure 1. Effect of current intensity on electrolysis of nicosulfuron 
Electrolysis experiments were performed under different current density and results were shown in Figure 1. Increasing current intensity had a positive influence on the degradation of nicosulfuron in the range of $0.3-1.0 \mathrm{~A}$. When the current intensity was $1 \mathrm{~A}$, its removal rate of nicosulfuron was almost the same as that of $0.8 \mathrm{~A}$. The removal rate of nicosulfuron reached and $83.3 \%$, respectively, after electrolyzing for $7 \mathrm{~h}$. The increase of current intensity has dual effect on the effect of electrolysis. On the one hand, the high current intensity can accelerate the oxidation rate of organic matter on the surface of the electrode, while it also accelerates the generation of indirect oxidant hydroxyl radicals $(\cdot \mathrm{OH})$ [6]. When the applied current intensity is too high, the formation of side products may hamper the generation and availability of $\cdot \mathrm{OH}$ radicals. If the current intensity is too low to meet the energy demand for the chemical bond breakage of nicosulfuron, the degradation process could not occur. Therefore, combining a variety of factors, the optimal current intensity selected in this experiment was $0.8 \mathrm{~A}$.

\subsection{Effect of electrode plate spacing}

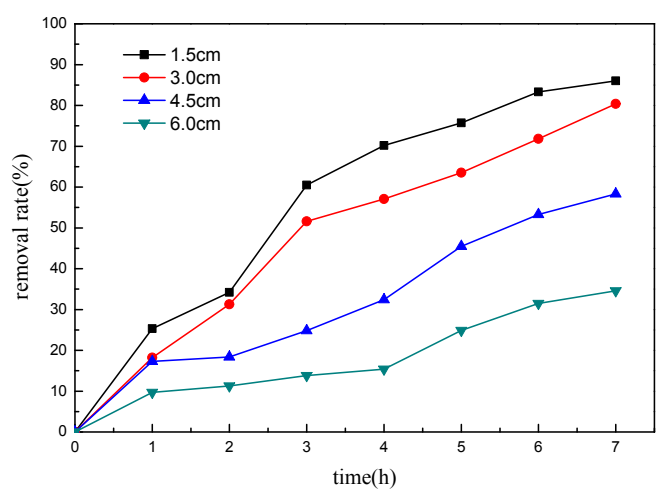

Figure 2. Effect of plate spacing on the electrolysis of nicosulfuron.

Electrolytic experiments were performed at different spacings to study the influence on the degradation of nicosulfuron and results were shown in Figure 2. It could be seen that when the distance between the plates was $1.5 \mathrm{~cm}$, the nicosulfuron solution had the highest electrolytic removal rate. In the same electrolyte system, the smaller the electrode spacing was, the shorter distance the electrons were demanded to transfer in the electrolyte, which is advantageous to increase the transmission of energy transfer during the electrolysis process. Therefore, the short distance is help to increase the electrolysis efficiency [7]. However, the excessively small plate spacing would lead to a low treating volume between the electrodes, which was not benefit the improvement of the processing efficiency. Herein, the plate distance of $3 \mathrm{~cm}$ was chosen for the rest of the experiment.

\subsection{Influence of electrolyte pH}

Solution $\mathrm{pH}$ is one of the important factors that affects the performance of electrochemical process. For incosulfuron, the acidity and alkalinity of the solution have a great influence on its hydrolysis process. In neutral solution, its hydrolysis rate is faster than in acidic solution or in alkaline solution and the half-life of hydrolysis is $5.2 \mathrm{~d}$. In acidic solution and alkaline solution, the half-life of hydrolysis is $7.7 \mathrm{~d}$ and $20.5 \mathrm{~d}$, respectively [8].

The effect of $\mathrm{pH}$ on the degradation of nicosulfuron in the electrolysis process may be different from that of natural hydrolysis. $\mathrm{pH}$ As a consequence, the effect of $\mathrm{pH}$ value ranging from 1 to 9 on the nicosulfuron degradation was investigated, and the results were presented in Figure 3. From Figure 3, it was found that the maximum removal rates of nicosulfuron was observed at $\mathrm{pH} 3$, which was $86.6 \%$ at $7 \mathrm{hrs}$. The minimum removal rate reached at $\mathrm{pH} 6$, suggesting that it was unfavorable for the degradation process of nicosulfuron in neutral condition. It might be due to the highest resistance of the solution and the lowest conductivity in the neutral solution, which led to the lowest removal rate of nicosulfuron [9]. The optimum reaction $\mathrm{pH}$ was 3.0 for the experiment.

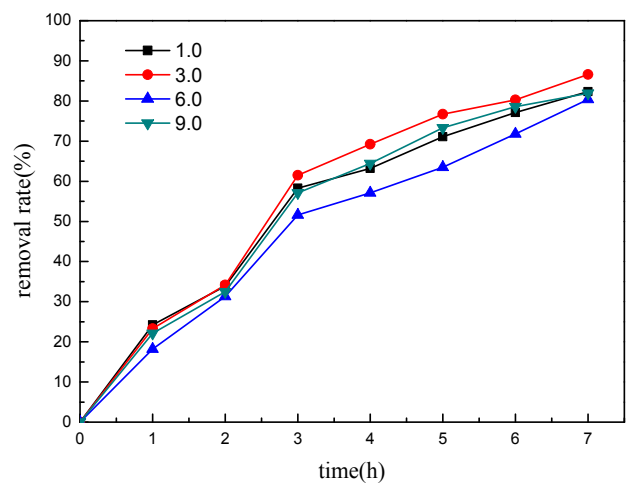

Figure 3. Effect of $\mathrm{pH}$ on the degradation of nicosulfuron

\section{Conclusion}

A method for the determination of nicosulfuron concentration by HPLC was established. The optimal condition of electrolysis was investigated to obtain highest removal rate for nicosulfuron. The results were shown as follows :

(1) HPLC, equipped with an inertSustain C18 column $(4.6 \mathrm{~mm} \times 150 \mathrm{~mm} \times 5 \mu \mathrm{m})$ could be used to determine the concentration of nicosulfuron. There was a good linear relationship between the peak area and the concentration of nicosulfuron solution in the range of 0 $100 \mathrm{mg} / \mathrm{L}$.

(2) No significant change of nicosulfuron was achieved in the electrolysis experiment after $7 \mathrm{~h}$ of agitation. The degradation of nicosulfuron caused by continuous stirring can be ignored.

(3) A double-coated titanium dioxide titanium plate was used as the anode accompanied with a single-coated titanium plate as the cathode. The highest removal efficiency of nicosulfuron was obtained when the electrolyte $\mathrm{pH}=3$, the plate spacing is $1.5 \mathrm{~cm}$ and the current intensity is $0.8 \mathrm{~A}$. Under the optimal condition, the 
highest removal rate could reach $86.6 \%$ after 7 hours electrolysis.

\section{Acknowledgment}

This work was supported by the Natural Science Foundation of Shandong Province, China (Grant No. ZR2014CM032).

\section{References}

1. Sabadie J. J AGR FOOD CHEM, 50, 3. (2002)

2. F. L. Chen, W.Q.Jiang., ICMSE, 30, 11 (2016)
3. Z. Q. Liu, J. Ma, Y. H. Cui, L. Zhao, B. P. Zhang, APPL CATAL B-ENVIRON. 101,74 (2010)

4. T. Velegraki, G. Balayiannis, Chem. Eng. J. 160,538(2010)

5. J. M. Chen, Y. J. Xia, Q. Z. Dai, Electrochimica Acta, 16,5 (2015)

6. W.J.Zhi. Harbin Institute of Technology, (2011)

7. L. B.Qi, S. Q. Zhong, Meng. W. Contemporary Chemical Industry. 20. 9. (2015)

8. L. Wan, Z. G. Hou, L. C. Li. Journal of Anhui Agricultural Sciences. 39, 25. (2011)

9. Y. Li, Shandong Institute of Light Industry, 61. 9. (2010) 